\title{
Evaluating Operational Performance of Intersections Using SIDRA
}

\author{
Prakash Ranjitkar ${ }^{*}$, Amin Shahin and Fasihullah Shirwali \\ Department of Civil and Environmental Engineering, University of Auckland, Auckland, New Zealand
}

\begin{abstract}
Traffic congestion has significant social, economic and environmental costs associated with it. Efficiency of intersections contributes significantly towards the efficiency of whole urban road networks as they are the main bottlenecks in the system. This paper presents a comparative analysis of the operational efficiency of priority controlled, roundabout and signalised intersections under a range of traffic conditions with different volume and turning ratios using SIDRA software. We used three measures to represent the operational efficiency namely: intersection capacity, average delay and total emissions. The analysis revealed strengths and weaknesses of each intersection types under a range of demand and traffic conditions. At low traffic demand, priority controlled intersections outperformed the other two forms of intersection control. At moderate traffic demand, roundabout performed the best while at high traffic demand, signalised intersections performed the best.
\end{abstract}

Keywords: Operational performance, priority controlled intersection, roundabout, SIDRA, signalised intersection.

\section{INTRODUCTION}

Intersection design is a complex process where factors related to operational efficiency such as capacity, delay and emissions are an important consideration along with safety features and geometrical constraints. A poorly designed intersection may contribute to traffic congestion, increase in vehicular emissions and road accidents. The operational efficiency of intersections largely depends on the prevailing road, traffic and control conditions. In recent years, vehicular emissions have also been a major factor in intersection design. Environmentally-friendly alternatives are more important than ever before to minimize carbon footprints contributed by transport sector.

Literatures on the comparative study of the operational efficiency of different intersection types are limited. The effective intersection capacity, average delay and total emission are the three most commonly used measures of the operational efficiency of intersections. Troutbeck and Brilon (1996) stated that the operational efficiency of an intersection (they particularly focused on delay) is heavily dependent on the gap acceptance parameters, which apply to stop and give-way controlled, roundabout and opposed turns in signal controlled intersections [1]. A study conducted by Florida Department of Transportation (FDOT) in 1995 revealed that roundabout performs the best at moderate traffic demand; while at low demand stop or give-way controlled intersection performs better than other intersection types [2]. Sisiopiku and Oh (2001) stated that each form of intersection control has its own unique advantages over other intersection types under certain traffic conditions [3]. Mandavilli et al. (2003) suggested that the roundabout

*Address correspondence to this author at the Department of Civil and Environmental Engineering, University of Auckland, Auckland, New Zealand; Tel: 619 9233515; Fax: 649 3737462;

E-mail: p.ranjitkar@auckland.ac.nz performs better than all other forms of intersection control [4]. Akcelik (2008) stated that to obtain viable results, the gap acceptance parameters must be accurate [5]. Vlahos et al. (2008) compared the efficiency performance of three different intersection types including all-way-stopcontrolled, unsignalised roundabout and signalised intersection based on models developed in SIDRA software [6]. They reported that signalised intersections outperform all other forms of intersection control including unsignalised roundabouts when the demand is high.

Sisiopiku and Oh (2001) noted that the three measures of the operational efficiency can be closely correlated, that is to say an intersection that has capacity to withstand extremely high traffic demand, is highly likely to have lower delay and queue length [3]. Vehicular emissions are relatively high around intersections as vehicles have to slow down or stop at intersections, producing more emissions than when they are travelling at a constant speed. The other factors that can influence vehicular emissions are traffic demand, vehicle types and types of intersection control. The latter is becoming more concern to traffic engineers [6]. Mustafa et al. (1993) stated that in general a signalised intersection produce $50 \%$ more emissions than an unsignalised roundabout [7]. Coelho et al. (2006) and Vlahos et al. (2008) reported that signalised intersections outperform other intersection types for higher traffic demand producing minimal emissions $[6,8]$.

More recently, a number of new developments are made in advancing the way to control traffic at intersections and also the methodology that can be used to evaluate their performances. Hallmark et al. (2011) suggested that roundabouts might not necessarily yield lower emissions compared to the traditional stop or signal control intersection as they found emissions are highly dependent on driver behaviour [9]. Esawey and Sayed (2013) presented an indepth literature review of existing methods to analyse the operational and the safety performance of unconventional 
intersection designs [10]. Chou and Nichols (2014) evaluated the performance of an unconventional intersection type called "triangabout" as an alternative form of intersection for nonthrough arterial movement. They reported based on their case study that delay was reduced by $50 \%$ and number of conflict points by $34 \%$ compared to the existing configuration [11]. Hummer et al. (2014) using a simple Highway Capacity Manual based macroscopic model evaluated where a meter might help to improve performance of a roundabout [12]. They found that signalized intersections generally produce lower delays than metered or unmetered roundabout in most of the tested cases. Chaudhry et al. (2011) investigated queue discharge behaviour at signalized intersection based on analytical model and microsimulation [13]. Later, Chaudhry and Ranjitkar (2013) found that, the fundamental assumption of traffic signal design, a constant saturation flow rate, is not realistic when compared with field data [14]. They proposed new models to represent queue discharge behaviour at stop line and derived the respective formulations for capacity, cycle time and green time. Sinha et al. (2013) proposed a more futuristic approach to control traffic at intersections, which they termed as "virtual traffic lights + " [15].

This paper reports an investigation conducted on the operational efficiency of three different intersection types namely priority (give-way and stop) controlled intersection, unsignalised roundabout and signalised intersection using SIDRA acronymed for Signalised \& Unsignalised Intersection Design and Research Aid [16]. The operational efficiency is measured based on the three mostly commonly used performance measures namely intersection capacity, average delay and total emissions. A range of traffic conditions is modelled in SIDRA to evaluate their effects, which include varying volume ratios (a ratio of major versus minor traffic volumes) and turning ratios (a ratio of left, through and right turning traffic volume). The rationales of using SIDRA software for this study is discussed briefly in the next section; followed by a methodology section providing the details model features and traffic conditions investigated in this study. In section 4 , the results are presented under three subheadings: effects of volume ratios, effects of turning ratios and benchmark total intersection demand (TID). Finally, the findings of this paper is summarised in the last section.

\section{SIDRA SOFTWARE}

We used SIDRA Intersection software to model the three intersection types under a range of traffic and control conditions. SIDRA is a micro-analytical software, which is widely used in traffic engineering for a lane-by-lane analysis of different intersection types. It uses traffic models coupled with an iterative approximation method to provide estimates of measures of effectiveness (MoE) such as intersection capacity, total delay, queue lengths and emission levels [16]. Most of the studies conducted on the operational efficiency of intersections have used this software. SIDRA is known to have advantages over other software model when making efficiency comparisons between different types of intersections [3]. The methods employed by SIDRA emphasize the consistency of capacity and performance analysis [17]. Unlike any other software, SIDRA provides reliable and consistent $\mathrm{MoE}$ output, which is an important property to make the comparison a viable one and also easy to establish. In SIDRA, priorities of movements at signalised intersections are identified by the user. The user must input gap acceptance parameters such as the critical gap and follow-up headway. The delays measurements using SIDRA can have advantage over other empirical methods as the latter only measures stopped and queuing delay, while total delay calculated by SIDRA includes geometric delay, queuing delay, acceleration and deceleration delays and stopped delay.

\section{METHODOLOGY}

We developed four SIDRA models of three different types namely; priority-controlled unsignalised intersections with give-way and stop control, unsignalised roundabout and signalised intersection as shown in Fig. (1). A four leg X intersection on a levelled terrain is modelled with a pair of aligned legs perpendicular to the other pair. Each approach has a single-lane with a lane width of 3.3 meter. In a priority controlled intersection, vehicles on major road have right-ofway. In a stop-controlled intersection, all vehicles on minor road must come to complete stop regardless of whether there is a conflicting vehicle present or not. Whereas in a give-way intersection, the vehicle on minor road may slow down before travelling through the intersection if no conflicting vehicles are present. In the case of unsignalised roundabout, all vehicles have to give-way to circulating traffic as well as vehicles coming from the right-hand-side approach. For all cases of roundabouts, an island diameter of 20 meters and an inscribed diameter of 36 meters are used.

For signalised intersections, an exclusive additional short right turn bay 100 meters in length is used at each approach. This exclusive right turn slot had to be deployed due to the fact that signalised intersections are highly sensitive to right turning traffic volume. Not including an exclusive right-turn bay, would have affected the performance of signalised intersections significantly. For phasing arrangement in signalised intersections, a simple two phase system is used with opposed right-turns movements. To simplify the analysis process, pedestrian movements are omitted from the analysis. We also assumed ideal weather and pavement condition for all intersection analysis.

Three different volume ratios tested include 1:1 (equal volumes on both roads), 1:1.5 (major road has 50\% more traffic volume than that of minor road) and 1:2 (major road has double traffic volume than that of minor road). Five different turning ratios are tested with increasing right-turn and left-turn volume ratios from 10 to $30 \%$ denoted as $(10$, $80,10),(10,70,20),(10,60,30),(20,70,10)$ and $(30,60$, 10 ), where the first two digits represent left-turn volume percentage, the middle two digits represent through traffic volume percentage, and the right two digits represent rightturn traffic volume percentage on all of the four approaches. For traffic composition, the proportion of heavy vehicle is kept at $10 \%$ for all cases, which is a typical case in Auckland, New Zealand. In the following section, we present results to demonstrate the effects of volume and turning ratios on the three MOEs. 


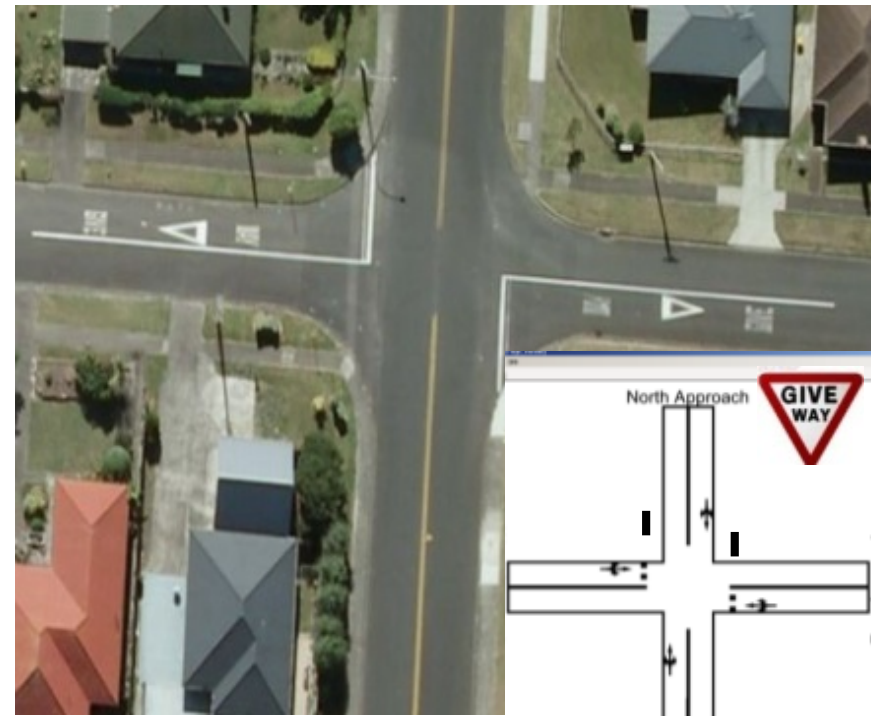

a) Give-way Controlled

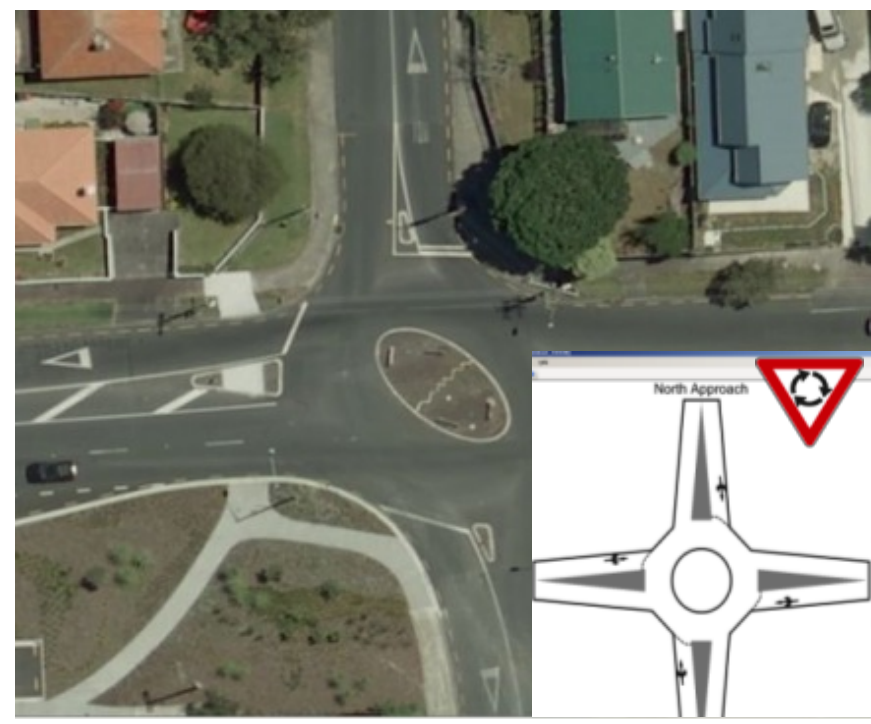

\section{c) Unsignalised Roundabout}

Fig. (1). Four different intersection types investigated in this study.

\section{ANALYSIS RESULTS}

The efficiency of intersections under different traffic and control conditions was measured based on three important measures of effectiveness (MOE) extracted from SIDRA output results namely intersection capacity (veh/hr), average delay (s/veh) and total emissions $(\mathrm{kg} / \mathrm{hr})$. The results presented in the next two sub sections are to quantify the effects of volume ratios and turning ratios on the efficiency of different intersection types. Then in the last sub section, benchmark values for each intersection types for optimal performance considering a particular MOE is presented and discussed.

\section{Effects of Volume Ratio}

When analysing the effects of varying volume ratios, the turning ratio was kept constant at $(10,80,10)$. Fig. (2)

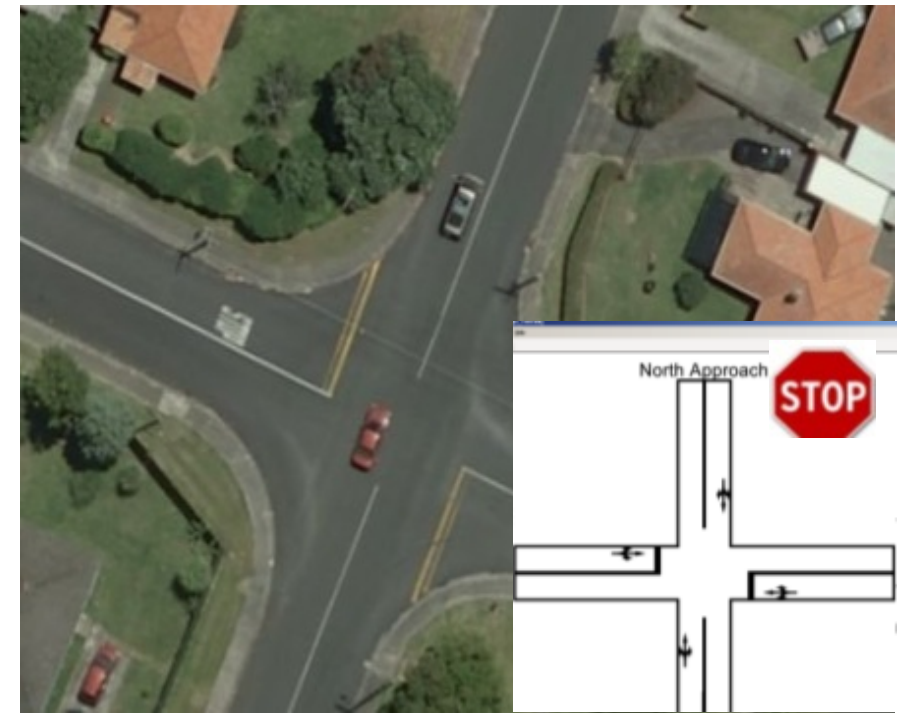

b) Stop Controlled

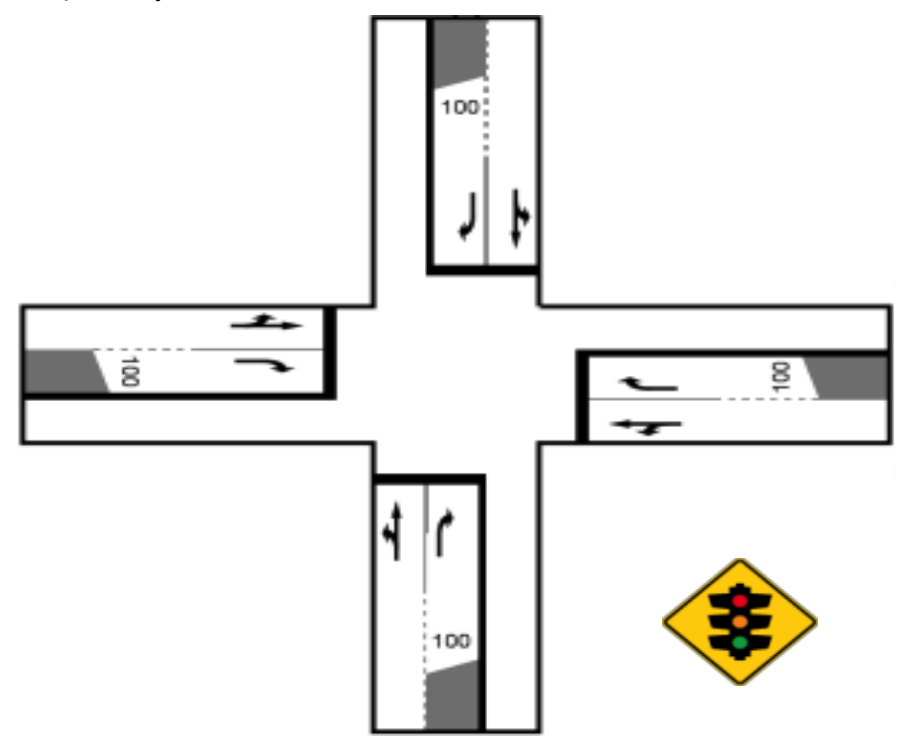

d) Signal Controlled

presents graphs showing the effects of volume ratios on capacity under the three different control conditions. Fig. (2a) presents results for a give-way controlled intersection. It shall be mentioned here that the results obtained for the stopcontrolled intersection was close to that of the give-way controlled intersection and hence not presented in this paper. The three curves generally follow the same trend where the effective intersection capacity decreases monotonously as TID increases. At very high TIDs the curves begin to level off. The first half of the graph (from about a TID of 1500 $\mathrm{veh} / \mathrm{hr}$ and below) shows that having a scenario where there is more vehicles on the major approaches compared to the minor approaches (such as a volume ratio of 1:2) results in higher intersection capacities as opposed to a balanced volume ratio such as a volume ratio of $1: 1$. At a TID of 1500 $\mathrm{veh} / \mathrm{hr}$, the curves cross over, and a more balanced volume ratio such as 1:1 begins to outperform the other two ratios. 


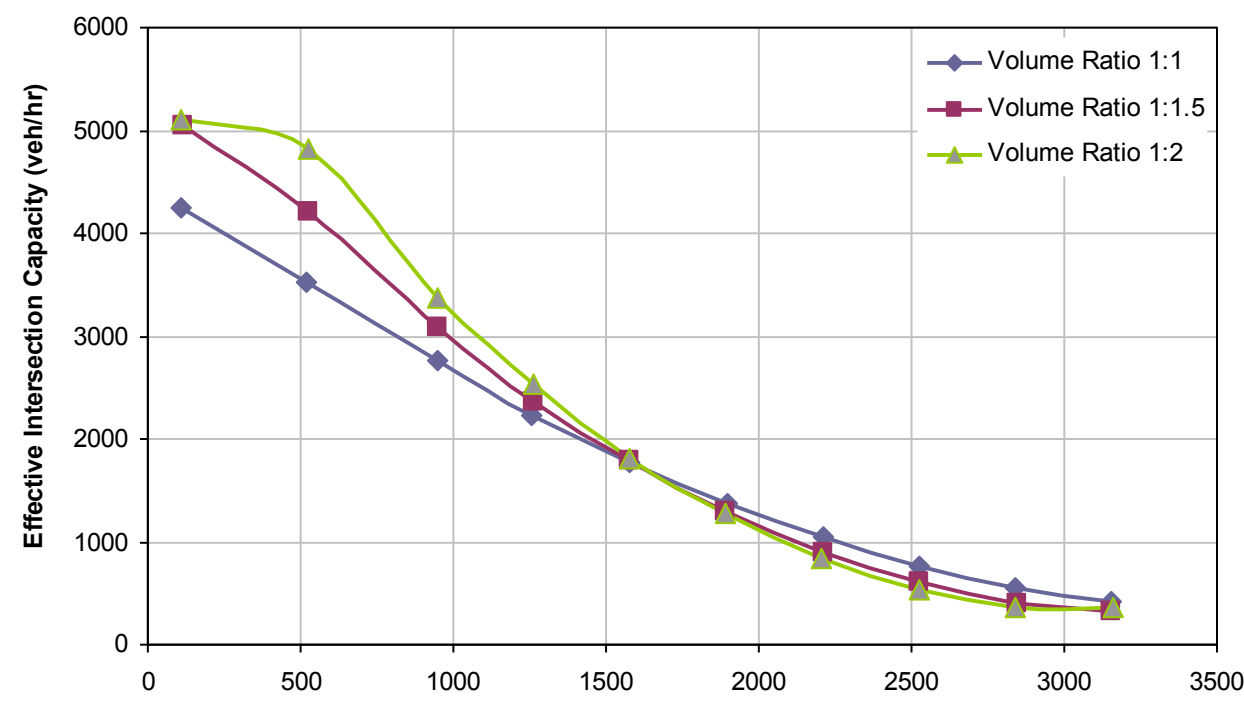

a)

Total Intersection Demand (veh/hr)

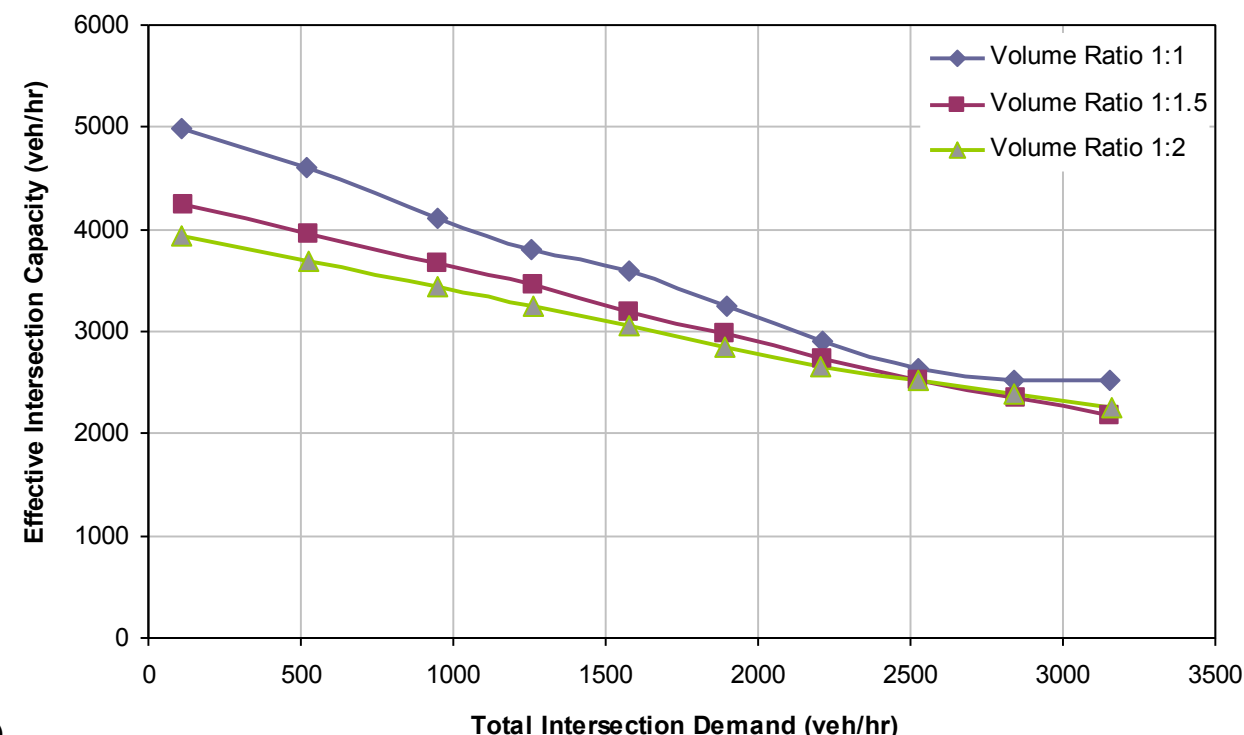

b)

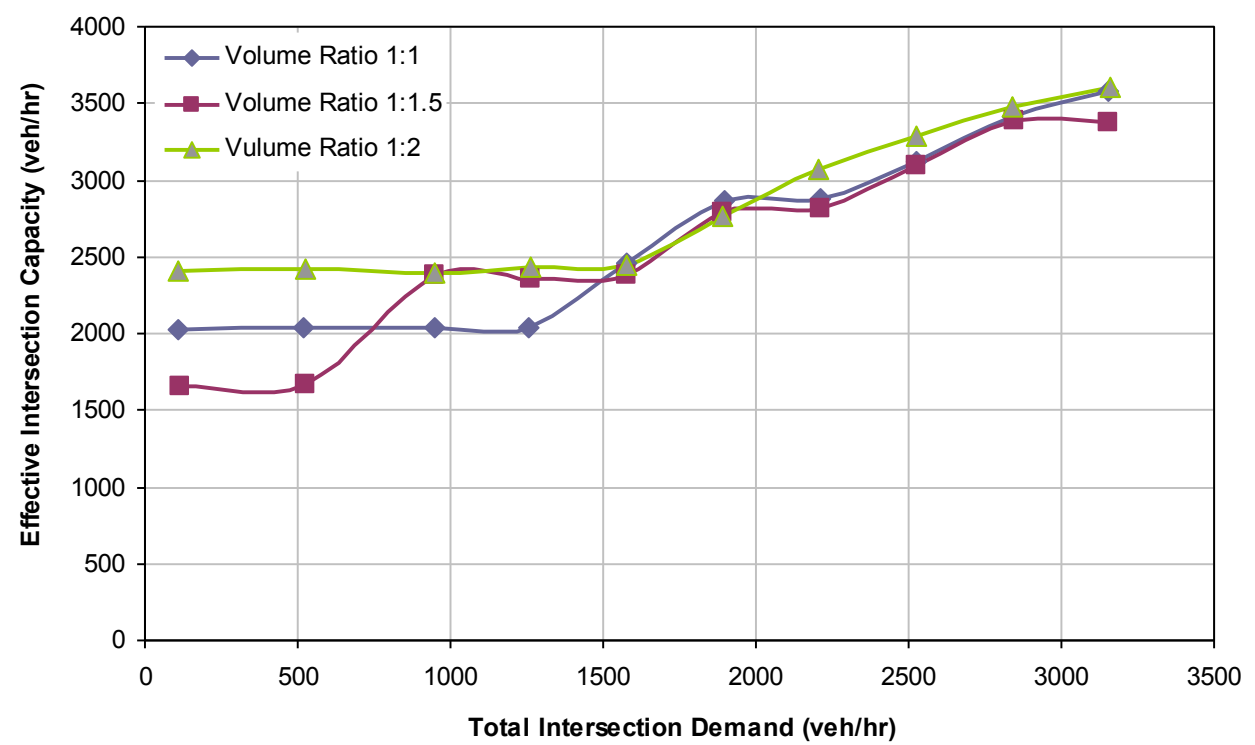

Fig. (2). Effect of volume ratios on intersection capacity; a) priority (give-way) controlled intersection; b) unsignalised roundabout; c) signalised intersection. 
This is due to the fact that at approximately $1500 \mathrm{veh} / \mathrm{hr}$, a scenario with a volume ratio such as 1:2 (where there is $66.6 \%$ more traffic on the major approaches) becomes too much to handle on those approaches and thus a more balanced volume ratio where the percentage of total traffic is equally distributed begins to outperform. Thus at TIDs below $1500 \mathrm{veh} / \mathrm{hr}$, scenarios where a greater percentage of vehicles are on the major approaches can result in higher intersection capacities. Whereas for TIDs over $1500 \mathrm{veh} / \mathrm{hr}$, it requires a more balanced volume ratio such as $1: 1$ to obtain more higher intersection capacities.

Fig. (2b) presents the results for an unsignalised roundabout. All the three volume ratios follow similar trend where the effective intersection capacity decreases monotonously with increase in TID. In general, a balanced volume ratio of 1:1 gives the best results with higher intersection capacities compared with the other two volume ratios. Only one cross over observed in this figure is between volume ratio $1: 1.5$ and volume ration $1: 2$ at a high TID value close to $2500 \mathrm{veh} / \mathrm{hr}$ beyond which volume ration 1:2 performs slightly better than volume ration $1: 1.5$. It shall be also noted that the effect of volume ratios on the effective intersection capacity is relatively high at low TID.

Fig. (2c) presents the results for a signalised intersection. It can be observed the effective intersection capacity increases as TID increases, which is a opposite trend when compared to the previous two cases of give-way controlled and unsignalised roundabout. An unbalanced volume ratio of 1:2 generally performs better than the other two; more particularly for low and high TIDs though there appears to be no logical sequence in which the three volume ratios are performing. For low TIDs, a balanced volume ratio 1:1 performed better than an unbalanced volume ratio of $1: 1.5$.

Fig. (3) presents the effects of volume ratios on the average delays experienced under different types of intersection control. In general, there is a consistency in the shape and trend of the curves observed for all the three intersection types, where the average delay remains nearly flat for low TIDs then it increases exponentially as TID increases. However scale-wise there is a significant difference in the average delay experienced under the three intersection types. The signalised intersection gives the minimum delay for higher TIDs compared to the other two. The impact of the volume ratios is not that significant for low TIDs. At higher TIDs the volume ratios start to perform differently under each intersection type. For give-way control and signalised intersections, the most unbalanced volume ratio of 1:2 outperformed the other two volume ratios, while for unsignalised roundabout a balanced volume ratio 1:1 outperformed the other two volume ratios to give relatively lower delay for the respective TIDs; though the different is not that significant.

Fig. (4) presents the effects of volume ratios on total emissions for a signalised intersection that includes emissions of carbon dioxide, carbon monoxide, hydrocarbons and nitrogen oxide. As observed in this figure, total emissions increases monotonously as TID increases. The influence of volume ratio is minimal on the total emissions. It might be due to the fact that it does not matter what approach the vehicles are coming from, they will be producing emissions either way. However volume ratio that produces extra delays might contribute for additional emissions, which is noticeable at high TIDs. Consequently, a balanced volume ratio 1:1 that produces relatively higher delays for a signalised intersection case, have a bit more emissions than the other two volume ratios.

\section{Effects of Turning Ratio}

Fig. (5) presents graphs showing the effects of turning ratios on the effective intersection capacity for different intersection types. For the first two intersection types (that is give-way and unsignalised roundabout), a general trend is that the effective intersection capacity decreases monotonously as TID increases; while an opposite trend can be observed for signalised intersection cases. A combination with heavy left turning ratio $(30,60,10)$ outperforms all other combinations for the first two intersection types. This might be due to the reason that left turning traffic creates minimal disturbances to opposing movements when compared with through and right turning traffic. On the other hand a combination with heavy right turning ratio $(10,60$, 30) performs the worst. This might be due to the fact that a higher level of disturbances is created by right turning vehicles.

No such definite trend can be observed for a signalised intersection as seen in Fig. (5c). At low TID, a balanced turning ratio $(10,80,10)$ and combinations with heavy left turning ratios $(30,60,10)$ and $(20,70,10)$ performed close to each other and better than the other two combinations while a combination with heavy right turning ratios $(10,60$, 30) performed the worst. At higher TID, all combinations performed close to each other where a combination $(10,70$, 20) performed slightly better than others.

Fig. (6) presents graphs showing the effects of turning ratios on the average delay for different intersection types. In general, there is a consistency in the shape and trend of the curves observed for all the cases, where the average delay remains nearly flat for low TIDs then it increases exponentially as TID increases. However scale-wise there is a significant difference in the average delay experienced under the three intersection types. The signalised intersection gives the minimum delay for higher TIDs compared to the other two. The impact of the turning ratios is not that significant for low TIDs. At higher TIDs the turning ratios start to perform differently under each intersection type. The trends are similar for the first two intersection types that is give-way controlled intersection and unsignalised roundabout, where a combination with heavy left turning ratios $(30,60,10)$ performed the best giving minimal delay compared with the other four combinations and a combination with heavy right turning ratios $(10,60,30)$ performed the worst. It might be due to the same reason as explained earlier left turning traffic produces minimum disturbance in an intersection.

For the signalised intersection cases, a combination with heavy left turning ratios $(30,60,10)$ performed the worst giving relatively higher delays compared with the other four combinations. Combinations with higher right turning ratios $(10,60,30)$ and $(10,70,20)$ performed better than others. This might be due to the fact that a single lane was used for both left turning and through movements while an exclusive short lane was allocated for right turning movement in the model. 


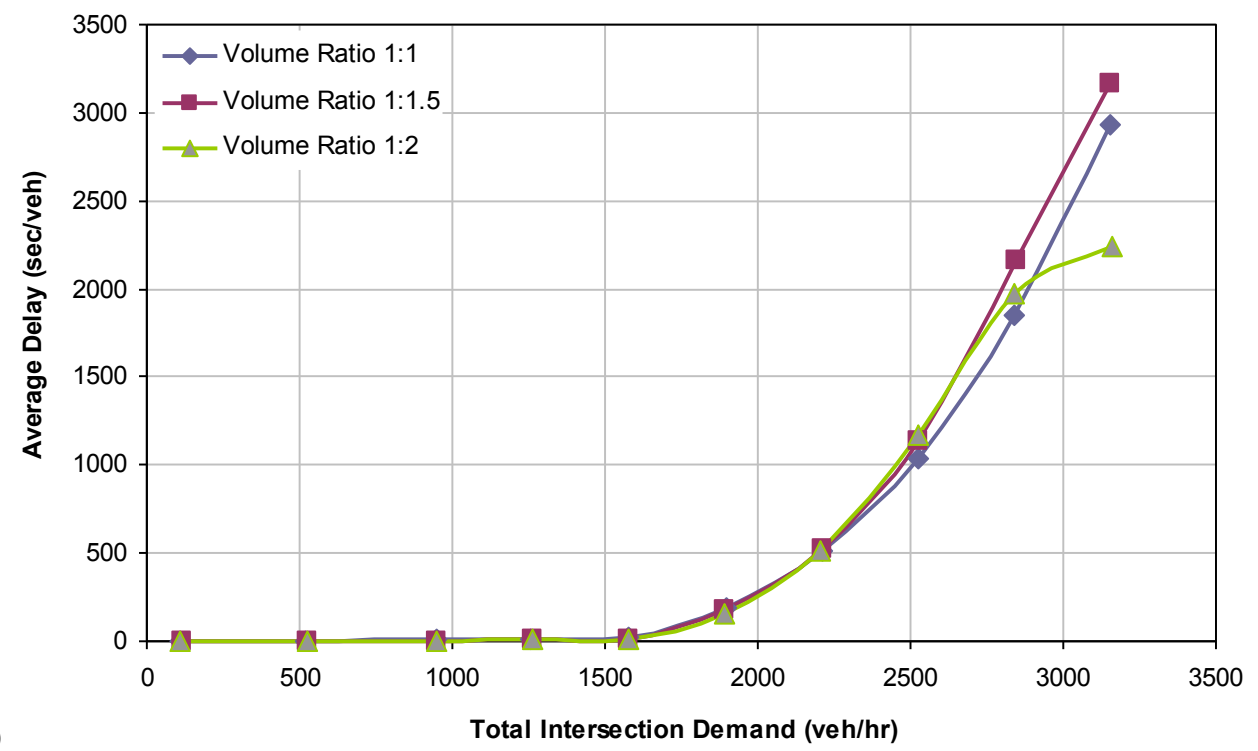

a)

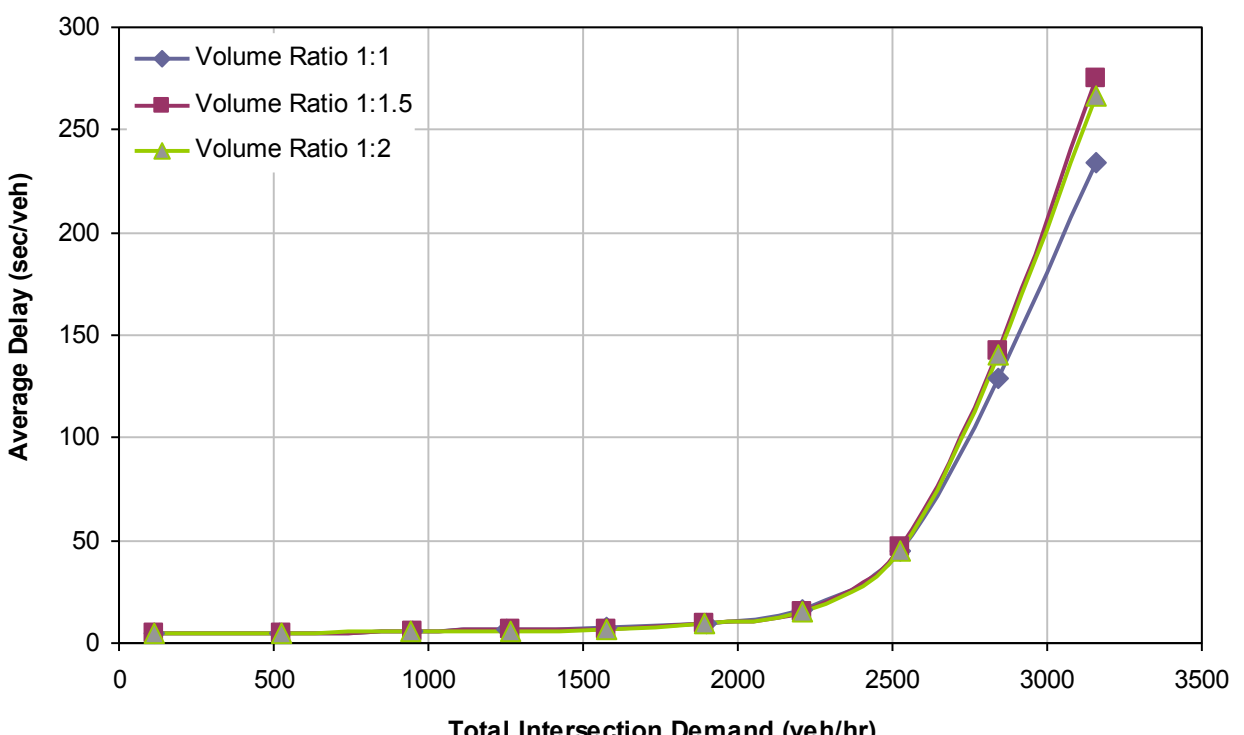

b)

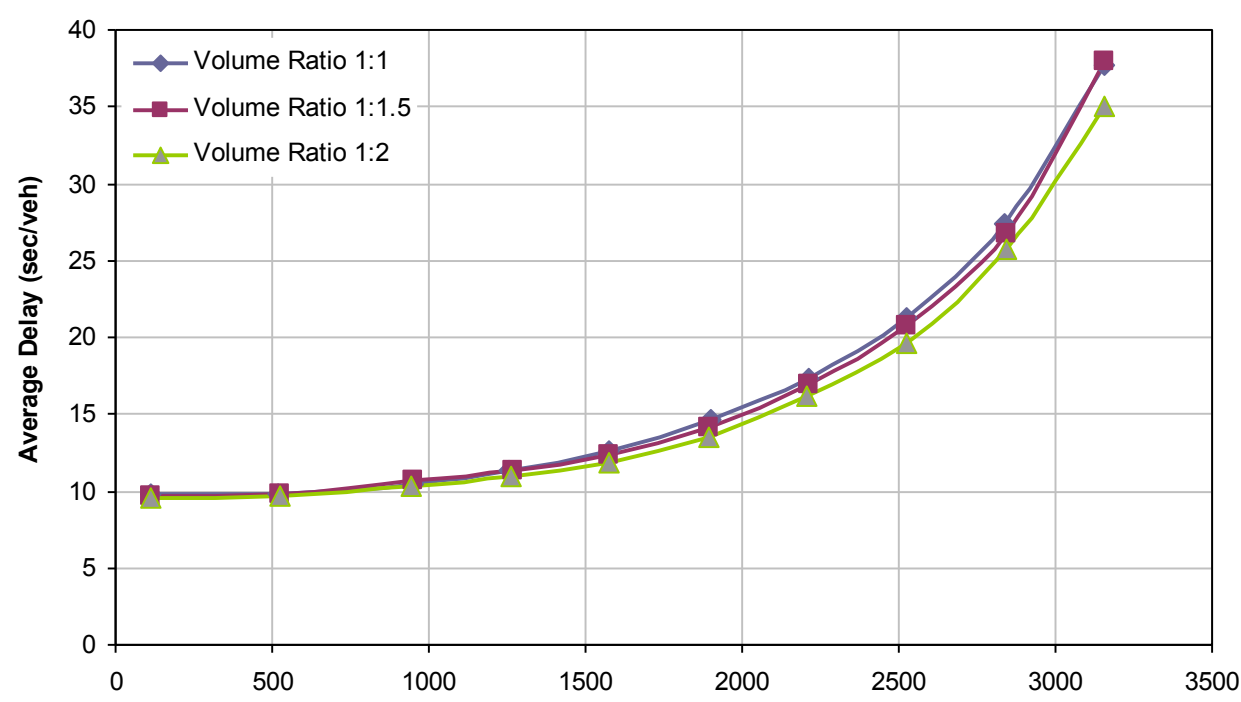

c)

Total Intersection Demand (veh/hr)

Fig. (3). Effects of volume ratios on average delays; a) priority (give-way) controlled intersection; b) unsignalised roundabout; c) signalised intersection. 


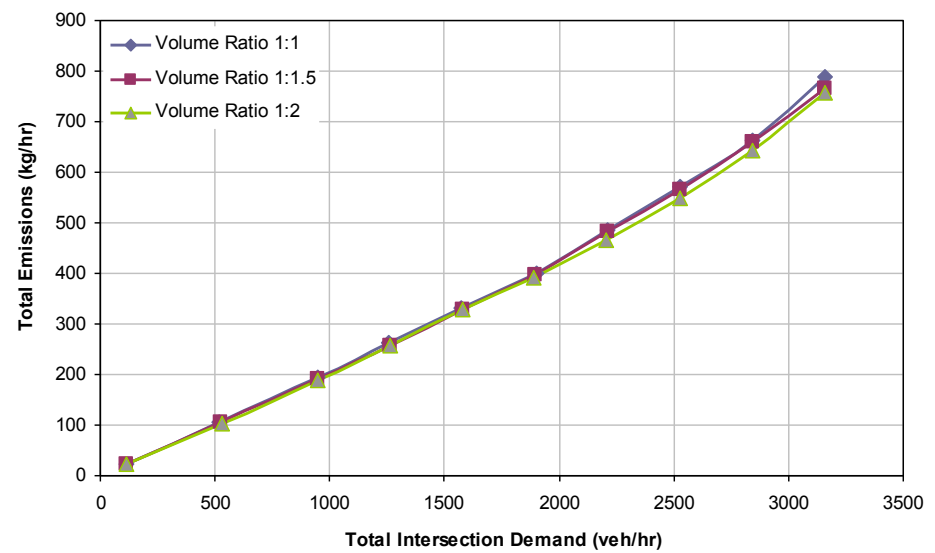

Fig. (4). Effect of volume ratios on total emissions for a signalised intersection.

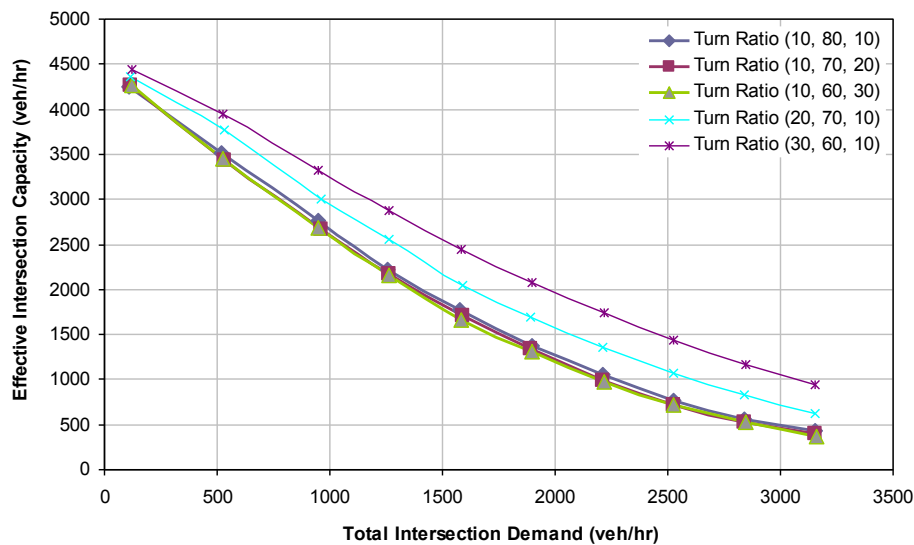

a)
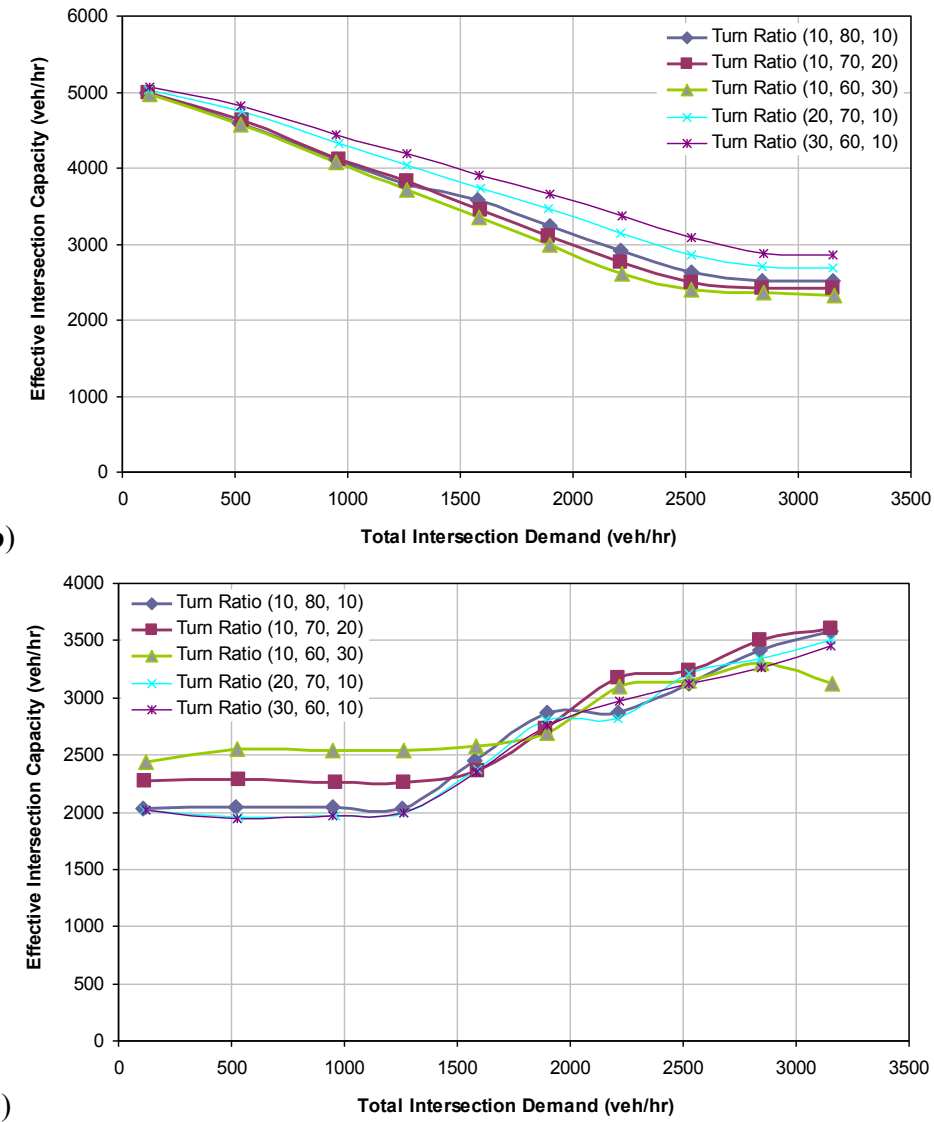

Fig. (5). Effects of turning ratio on intersection capacity; a) priority (give-way) controlled intersection; b) unsignalised roundabout; c) signalised intersection. 


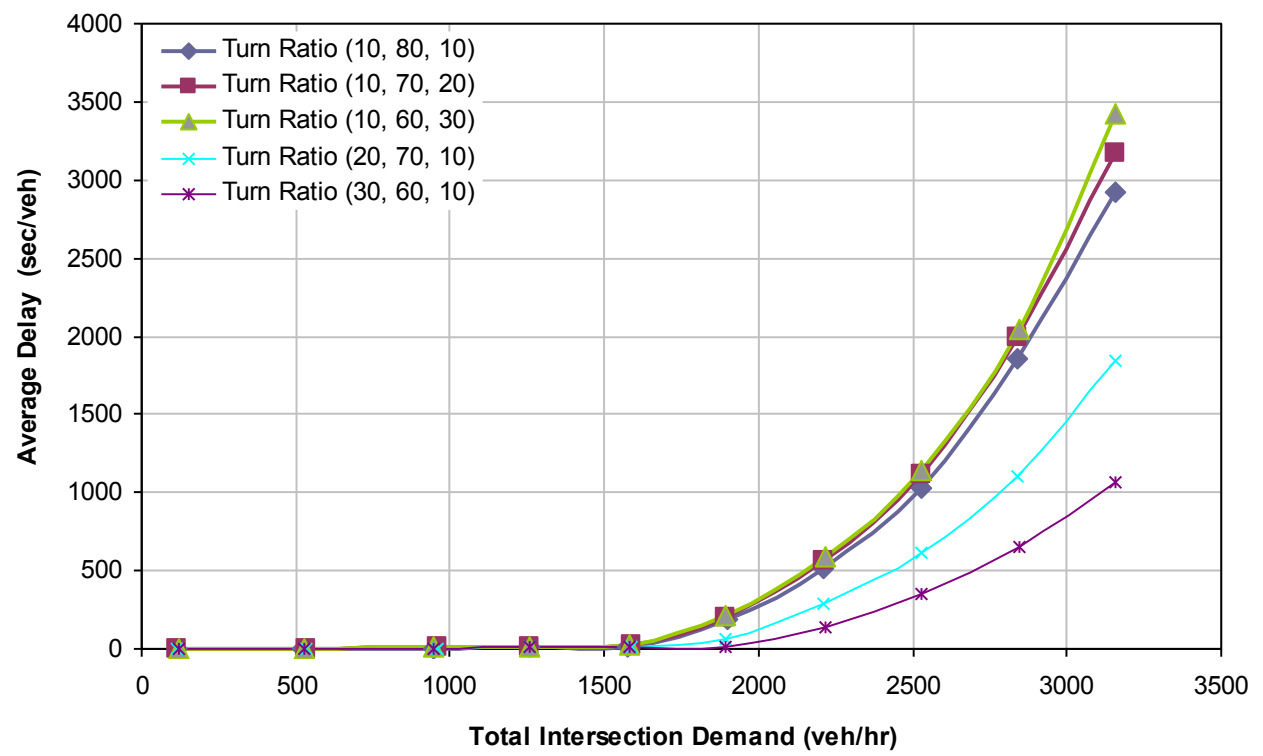

a)

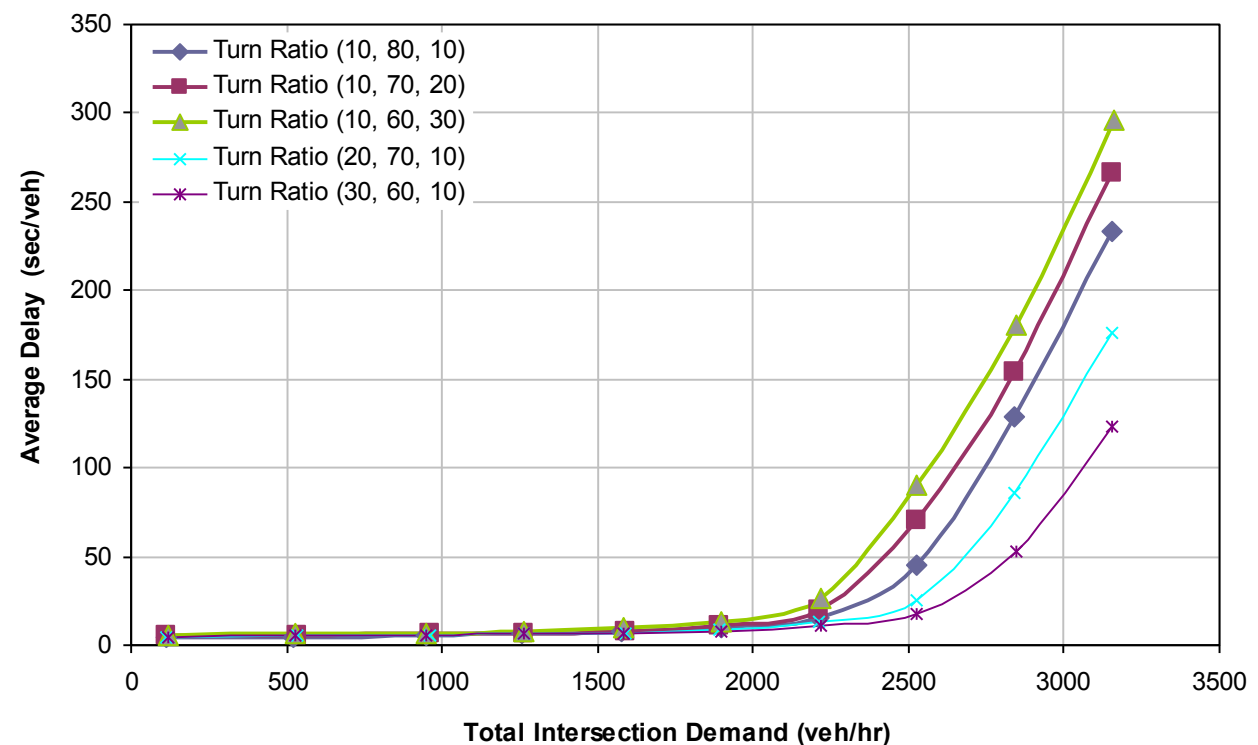

b)

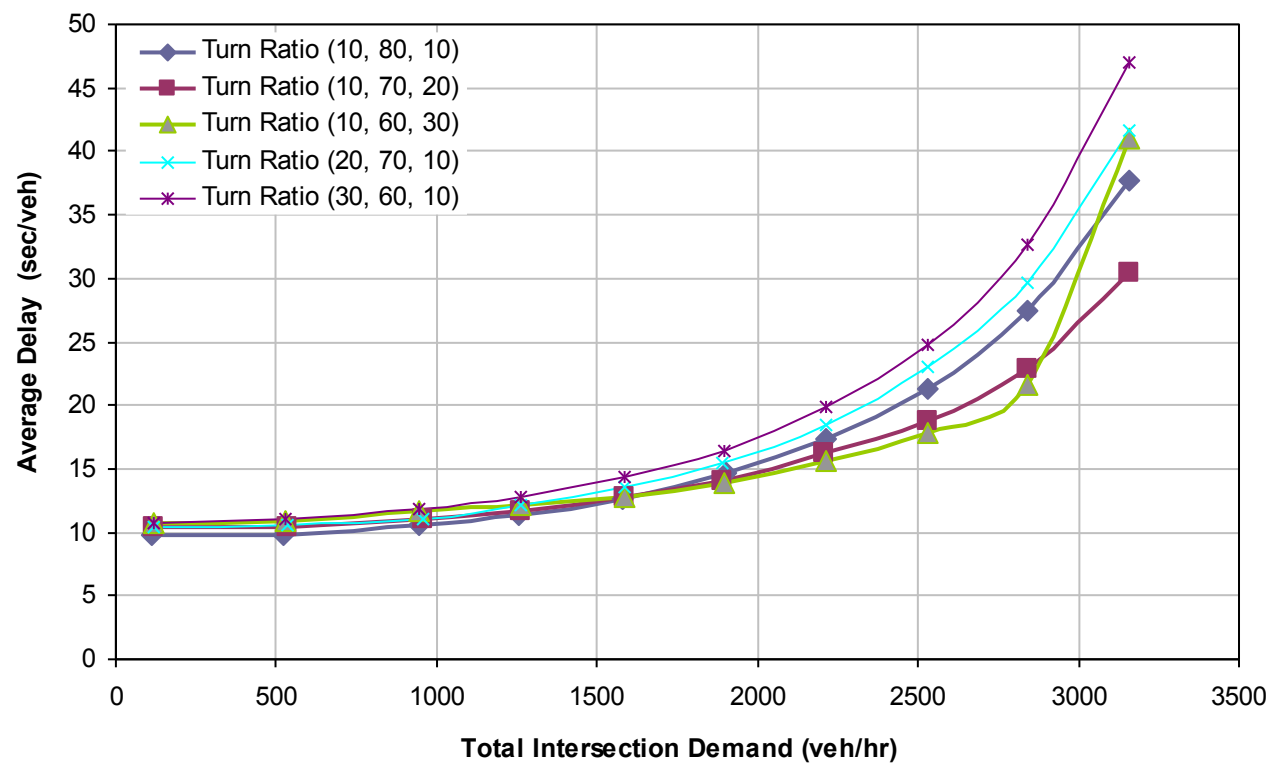

Fig. (6). Effects of turning ratio on average delay; a) priority (give-way) controlled intersection; b) unsignalised roundabout; c) signalised intersection. 
Fig. (7) presents the effects of turning ratios on total emissions for a signalised intersection. As observed in this figure, total emissions increases monotonously as TID increases. The influence of turning ratios is minimal on the total emissions. A combination with heavy left turning ratio $(30,60,10)$ performed the worst as the same ratio produces relatively higher delays compared with the other four combinations.

\section{Benchmark TID's}

Fig. (8) presents one of the many graphs used to determine a benchmark TID value representing optimal performance of a particular intersection type based on the effective intersection capacity. All the four intersection types are plotted and compared to determine the benchmark TID value. It shall be noted that as the give-way and stop controlled intersections perform closely, they are represented by a single line in this figure. A point of intersection between two curve lines represents the TID value at which one intersection type starts to perform better than the other. At low demand with TIDs in a range of 0 to approximately 600 $\mathrm{veh} / \mathrm{h}$, give-way and stop controlled intersections yield the highest intersection capacities and hence outperforms all other intersection types. At moderate demand with TID in a range of 600 to $2000 \mathrm{veh} / \mathrm{h}$, the unsignalised roundabout starts to perform better than the other two intersection types. At high demand with TIDs over $2000 \mathrm{veh} / \mathrm{h}$, signalised intersections starts to perform better than the other two intersection types. Similar graphs were plotted for each volume and turning ratios to obtain a table of benchmark TID values presented in Table 1 .

Fig. (9) presents a figure showing how a benchmark TID value is determined based on the average delay. As seen in this figure, all the three intersection types perform close to

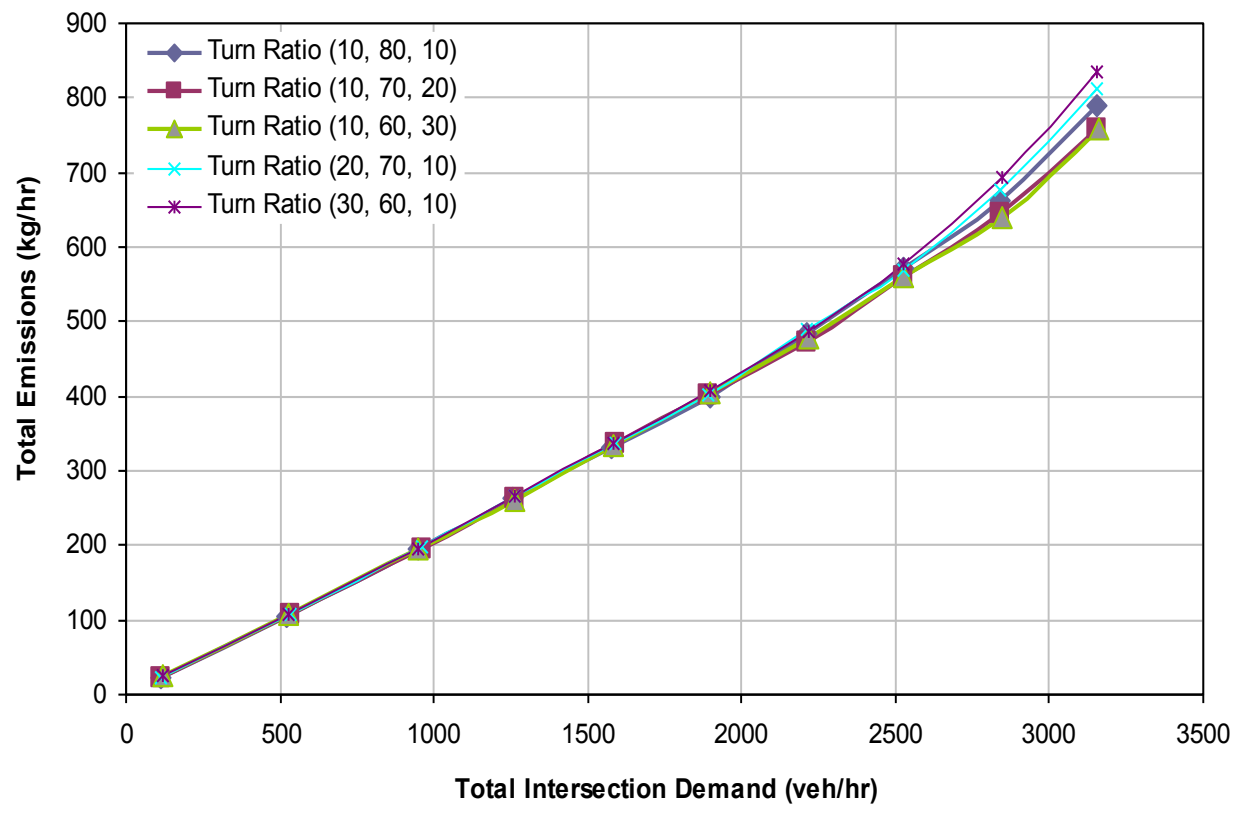

Fig. (7). Effects of turning ratio on total emissions for a signalised intersection.

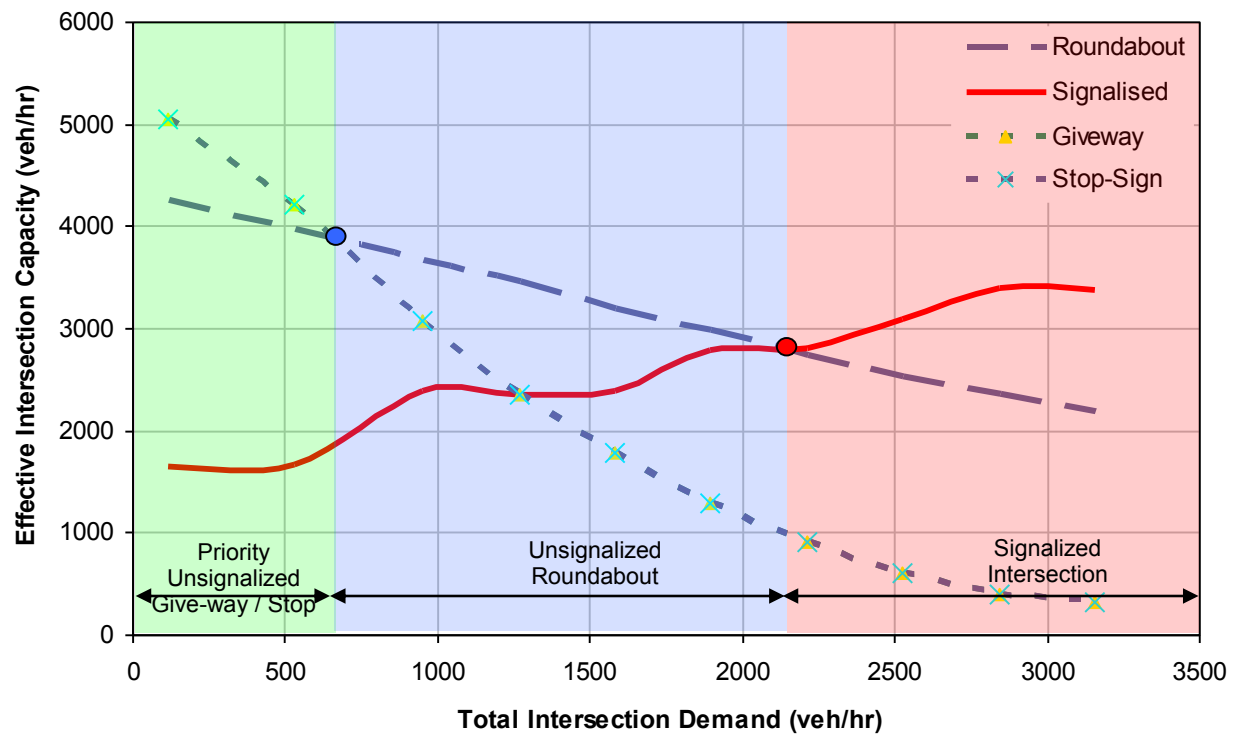

Fig. (8). Benchmark TID establishment based on effective intersection capacity. 


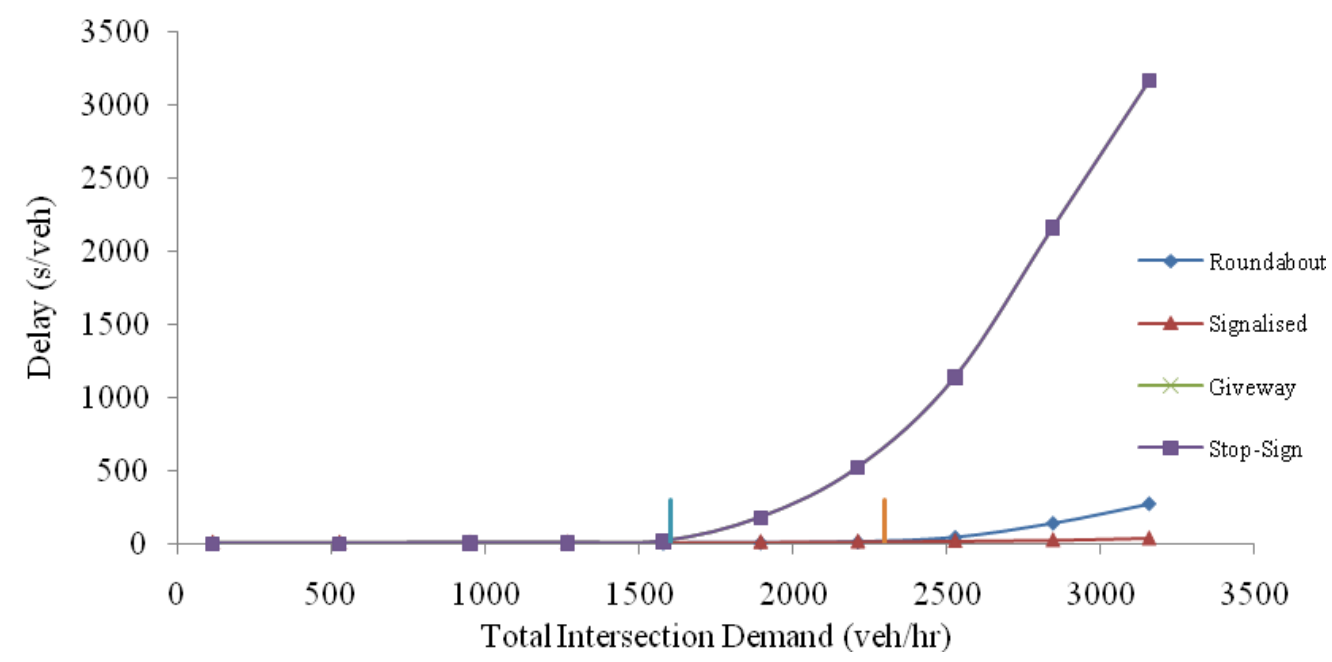

Fig. (9). Benchmark TID establishment based on average delay.

each other at low TIDs. At around $1550 \mathrm{veh} / \mathrm{h}$, giveway/stop controlled intersections start to experience higher average delay than the other two while the other two intersection types that is unsignalised roundabout and signalised intersection are still performing close to each other. At approximately $2400 \mathrm{veh} / \mathrm{h}$, the unsignalised roundabout starts to experience higher average delays than the signalised intersection. At TIDs higher than $2400 \mathrm{veh} / \mathrm{h}$, the signalised intersection yields the lowest average delays and outperforms the other two intersection types. Similar comparisons are made to compute benchmark TID values based on queue length and total emissions as presented in Table 1.

Table 1. Maximum TID values for different intersection types.

\begin{tabular}{|c|c|c|c|c|c|c|c|c|c|c|c|c|c|}
\hline \multirow{3}{*}{ 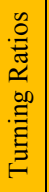 } & \multirow{3}{*}{ Intersection Type } & \multicolumn{12}{|c|}{ Volume Ratios } \\
\hline & & \multicolumn{4}{|c|}{1.0} & \multicolumn{4}{|c|}{1.5} & \multicolumn{4}{|c|}{2.0} \\
\hline & & Capacity & Delay & Queue & $\begin{array}{c}\text { Total } \\
\text { Emissions }\end{array}$ & Capacity & Delay & Queue & $\begin{array}{c}\text { Total } \\
\text { Emissions }\end{array}$ & Capacity & Delay & Queue & $\begin{array}{c}\text { Total } \\
\text { Emissions }\end{array}$ \\
\hline \multirow{3}{*}{$\begin{array}{l}0 \\
0 \\
\infty \\
0 \\
0\end{array}$} & Stop \& Giveway & -- & 860 & $1100 * *$ & $1580 * *$ & 660 & $1250^{* *}$ & $1250^{* *}$ & $1580 * *$ & 920 & $1200^{* *}$ & $1400 * *$ & $1620^{* *}$ \\
\hline & Stop \& Giveway* & 1330 & 1480 & 1480 & $1580^{* *}$ & 1270 & 1490 & 1450 & $1580 * *$ & 1300 & 1530 & 1550 & $1620^{* *}$ \\
\hline & Roundabout & 2240 & 2250 & 2200 & $2240 * *$ & 2100 & 2230 & 2150 & $2200 * *$ & 1950 & 2230 & 2190 & $2200^{* *}$ \\
\hline \multirow{3}{*}{$\begin{array}{l}\stackrel{i}{ } \\
0 \\
\stackrel{1}{0} \\
0\end{array}$} & Stop \& Giveway & -- & 920 & $1100 * *$ & $1580 * *$ & 660 & $1250^{* *}$ & $1250^{* *}$ & $1580 * *$ & 970 & $1200 * *$ & $1400 * *$ & $1620^{* *}$ \\
\hline & Stop \& Giveway* & 1210 & 1390 & 1390 & $1580 * *$ & 1190 & 1470 & 1400 & $1580 * *$ & 1190 & 1530 & 1520 & $1620^{* *}$ \\
\hline & Roundabout & 2040 & 2150 & 1900 & $2180 * *$ & 1990 & 2080 & 1820 & $2170 * *$ & 1850 & 2030 & 1800 & $2150^{* *}$ \\
\hline \multirow{3}{*}{$\begin{array}{l}0 \\
0 \\
8 \\
8 \\
0 \\
0\end{array}$} & Stop \& Giveway & -- & 1050 & $1100 * *$ & $1580 * *$ & 710 & $1250^{* *}$ & $1250^{* *}$ & $1580 * *$ & 1020 & $1200 * *$ & $1400 * *$ & $1620^{* *}$ \\
\hline & Stop \& Giveway* & 1030 & 1370 & 1370 & $1580 * *$ & 1310 & 1450 & 1320 & $1580 * *$ & 1060 & 1530 & 1470 & $1620^{* *}$ \\
\hline & Roundabout & 2020 & 2050 & 1580 & $2100 * *$ & 1570 & 1900 & 1600 & $2050 * *$ & 1220 & 1880 & 1520 & $1880^{* *}$ \\
\hline \multirow{3}{*}{$\begin{array}{l}\stackrel{0}{1} \\
\stackrel{i}{i} \\
\stackrel{i}{i}\end{array}$} & Stop \& Giveway & -- & 820 & 1610 & $1680^{* *}$ & 760 & $1570^{* *}$ & $1550^{* *}$ & $1680 * *$ & 1120 & $1200^{* *}$ & $1560 * *$ & $1790^{* *}$ \\
\hline & Stop \& Giveway* & 1480 & 1610 & $1400 * *$ & $1680^{* *}$ & 1480 & 1600 & 1590 & $1680 * *$ & 1570 & 1630 & 1650 & $1790 * *$ \\
\hline & Roundabout & 2370 & 2500 & 2490 & $2450 * *$ & 2190 & 2460 & 2300 & $2420 * *$ & 2190 & 2420 & 2290 & $2420^{* *}$ \\
\hline \multirow{3}{*}{$\begin{array}{l}0 \\
0 \\
0 \\
0 \\
0 \\
\dot{n}\end{array}$} & Stop \& Giveway & -- & 820 & $1400 * *$ & $1900 * *$ & 940 & $1570^{* *}$ & $1550^{* *}$ & $1890 * *$ & 1670 & $1200 * *$ & $1850 * *$ & $1990 * *$ \\
\hline & Stop \& Giveway* & 1620 & 1880 & 1880 & $1900 * *$ & 1720 & 1800 & 1850 & $1890 * *$ & 1780 & 1910 & 1920 & $1990 * *$ \\
\hline & Roundabout & 2510 & 2650 & 2630 & $2600 * *$ & 2320 & 2620 & 2530 & $2540 * *$ & 2250 & 2590 & 2500 & $2510^{* *}$ \\
\hline
\end{tabular}

** indicates that up to that particular value, both intersection types perform very similarly if not exactly the same.

a) Under the column "intersection type" three scenarios are presented:

b) Stop \& Giveway: The TID values in this row indicate the benchmark efficiency at which a give-way/stop controlled intersection performs the best. Any TID above these values would recommend a roundabout.

Stop \& Giveway*: The TID values in this row indicate the benchmark efficiency at which a give-way/stop controlled intersection performs the best. Any TID above these values would recommend a signalised intersection.

Roundabout: The TID values in this row indicate the benchmark efficiency at which a roundabout performs the best. Any TID above these values would recommend a signalised intersection. 
The benchmark TID values presented in Table $\mathbf{1}$ are in $\mathrm{veh} / \mathrm{h}$; represents a value up to which that a particular intersection type performs better than the other two intersection types for the respective MOE. After this value, the next intersection type in a sequence starting with giveway/stop followed by unsignalised roundabout and then signalised intersection starts to perform better than the one. For volume ratio 1:1 under the column for intersection capacity, the give-way/stop controlled intersection yield no values as the unsignalised roundabout performs better than the one. The benchmark TID values generally tend to increase for unbalanced volume ratios (1:1.5 and 1:2); indicating the give-way/stop controlled intersection becoming more effective under those TIDs and hence taking higher TID values for the crossover points. For priority controlled intersection and unsignalised roundabout, the crossover points appear at lower values as right turning ratio increases showing negative impact of right turning movements on the operational efficiency of intersections. While left turning movement found to have positive impact on the operational efficiency evident from increasing value for the crossover points as left turning ratio increases.

\section{CONCLUDING REMARKS}

This paper has assessed and compared the operational efficiency of three different intersection types namely priority (give-way and stop) controlled intersection, unsignalised roundabout and signalised intersection using SIDRA software. The operational efficiency is measured based on the three mostly commonly used performance measures namely intersection capacity, average delay and total emissions. We modelled a range of traffic conditions to evaluate their effects on the operational efficiency, which include three volume ratios with an increasing ratio of major versus minor traffic volumes and five turning ratios with an increasing left turning and right turning ratios.

Each of the three intersection types investigated in this study found to have some advantages over others under certain traffic conditions. At low TIDs, give-way and stop controlled intersections perform the best while unsignalised roundabouts perform the best at moderate TIDs. Signalised intersections outperform all other forms of intersection control at high TIDs.

In general, right turning movements impacts negatively on the operational efficiency of priority controlled intersection as well as unsignalised roundabout. While left turning movement found to have positive impact on the operational efficiency. For higher traffic demand, signalised intersections experience minimal delay and produce minimal emissions compared to the other two intersection types.

It shall be noted that the results presented in this paper are based on gap acceptance parameters for New Zealand driving conditions. They subjects to the limitations of SIDRA software, which is used for modelling as referred in literatures as the best suited software for this type of research. We investigated two important factors to describe traffic conditions at intersections namely volume ratio and turning ratio there are a number of other factors that might also influence the operational efficiency of intersections including approach grades, angle between intersection legs, pedestrian and cyclist movements and so on. All these factors need to be considered in practice including gap acceptance parameters values collected from field when selecting an intersection type for a particular situation.

\section{CONFLICT OF INTEREST}

The authors confirm that this article content has no conflict of interest.

\section{ACKNOWLEDGEMENTS}

Declared none.

\section{REFERENCES}

[1] R. J. Troutbeck, and W. Brilon, "Unsignalised Intersection Theory," In: N. Gartner, C. J. Messner, and Rathi A. K., Eds., Traffic Flow Theory, Transportation Research Board Special Report, 2000.

[2] FDOT. Florida roundabout design guide, Florida Department of Transportation (FDOT), 1995

[3] V. P. Sisiopiku, and H. Oh, "Evaluation of roundabout performance using SIDRA," J. Transp. Eng-ASCE, vol. 127, no. 2, pp. 143-150, April 2001

[4] S. Mandavilli, E. R. Russel, and M. J. Rys, Impact of modern roundabouts on vehicular emissions, Proceedings of Mid-Continent Transportation Research Symposium, Ames, Iowa, August, 2003.

[5] R. Akcelik, A Review of Gap-Acceptance Capacity Models, $29^{\text {th }}$ Conference of Australian Institutes of Transport Research (CAITR 2007), University of South Australia, Adelaide, Australia, 5-7 December 2007.

[6] E. Vlahos, A. Polus, D. Lacombe, P. Ranjitkar, A. Faghri, and B.R Fortunato, "Evaluating the Conversion of All-Way Stop Controlled Intersections into Roundabouts," Transport. Res. Rec., no. 2078, pp. 80-89, 2008.

[7] S. Mustafa, A. Mohammed, and S. Vougias, Analysis of Pollutant Emissions and Concentrations at Urban Intersections, Compendium of Technical Papers, Institute of Transportation Engineers, 1993.

[8] M. C. Coelho, T. L. Farias, and N. M. Rouphail, "Effects of roundabout operations on pollutant emissions," Transport. Res. DTr. E, vol.11, issue 5, pp. 333-343, 2006.

[9] S. L. Hallmark, B. Wang, A. Mudgal, and H. Isebrands, "On-Road Evaluation of Emission Impacts of Roundabouts," Transport. Res. Rec., no. 2265, pp. 226-233, 2011.

[10] M. E. Esawey and T. Sayed, "Analysis of unconventional arterial intersection designs (UAIDs): state-of-the-art methodologies and future research directions," Transportmetrica A, vol. 9, no. 10, pp. 860-895, 2013

[11] C. S. Chou, and A.P. Nichols, "Evaluation of triangabout as alternative for intersection with nonthrough arterial movement," Transport. Res. Rec., no. 2404, pp. 38-48, 2014.

[12] J. E. Hummer, J. S. Milazzo, and B. Schroeder, "Potential for metering to help roundabouts manage peak period demands in the United States," Transport. Res. Rec., no. 2402, pp. 56-66, 2014

[13] M. S. Chaudhry, P. Ranjitkar, and D. J. Wilson. "Investigation of Queue Discharge Behavior at Signalized Intersection based on Analytical and Micro-simulation Models," Journal of Eastern Asia Society for Transportation Studies, Vol. 9, pp. 1628-1643, 2011.

[14] M. S. Chaudhry, and P. Ranjitkar, "Delay Estimation at Signalized Intersections with Variable Queue Discharge Rate," Journal of Eastern Asia Society for Transportation Studies, Vol. 10, pp. 1764$1775,2013$. 
[15] R. Sinha, P. S. Roop, and P. Ranjitkar, "Virtual Traffic Lightst: A Robust, Practical, and Functionally-Safe Intelligent Transportation System," Transp. Res. Rec., vol. 2381, pp. 73-80, 2013.

[16] R. Akcelik, and M. Besley, SIDRA 5 User Guide, ARRB Transport Research Ltd., 1999.
[17] R. Akcelik, "Lane-by-lane modelling of unequal lane use and flares at roundabouts and signalised intersections: The SIDRA solution," Traffic Engineering and Control, 38 (7/8), pp. 388-399, 1997.

(C) Ranjitkar et al.; Licensee Bentham Open.

This is an open access article licensed under the terms of the Creative Commons Attribution Non-Commercial License (http://creativecommons.org/licenses/by$\mathrm{nc} / 3.0 /$ ) which permits unrestricted, non-commercial use, distribution and reproduction in any medium, provided the work is properly cited. 